the claim pack has a framework originally devised in relation to physical disability, and appeals have to be framed in that context. For example, a patient may be able to dress himself, get a take-away, go out on his own to the betting shop, and yet be severely mentally disabled and need supervised care for his own and others' safety.

Perhaps the College, through its Rehabilitation Section, may be stimulated to set up a working party, in conjunction with the involved voluntary agencies, to review the working of the current benefit systems in relation to the needs of people with a severe mental illness. Such a project might throw up ideas on ways to improve the current state of affairs, for the benefit of the most needy of our patients.

Further information on the DLAAB and its activities can be obtained from its website (http://www. dlaab.org.uk/).

\section{Acknowledgements}

I thank Professor Grahame, Chairman of the DLAAB, and the DLAAB Secretariat for their help in preparation of this article. The further thoughts expressed at the end of this article are entirely the personal view of the author, and in no way related to the work of the Board.

\section{References}

DEPARTMENT OF SOCIAL SECURITY DISABILITY LIVING ALLOWANCE (1998) The Disability Handbook. A ADVISORY BOARD (2000) Handbook on the Care Needs and Annual Report 1999. (http:// Mobility Requirements likely to Arise www.dlaab.org.uk/pubs/ar99/ from Various Disabilities and Chronic Illness. London: The Stationery Office.

-(2000) Disability Care and Mobility Benefits - August 1999 Quarterly Statistical Enquiry. Government Statistical Service Press Release, 17 February 2000. http:// www.dss.gov.uk/mediacentre/ pressreleases/2000/feb/00046. pdf

- (2001) Disability Care and Mobility Benefits - February 2001 Quarterly Statistical Enquiry. Government Statistical Service Press Release, 19 July 2001. http://www.dss.gov.uk/asd/ asd1/dla-aa-ica-feb2001.pdf. ar99.htm). INLAND REVENUE (1999) Working FamiliesTax Credit and Disabled Person'sTax Credit (http:// www.inlandrevenue.gov.uk/wftc/ index.htm).

KILLOUGHERY, M. (1999) Disability and incapacity benefits. The role that doctors play. Psychiatric Bulletin, 23 260-263.

LUCAS, R. (1998) Alcohol abuse. DLAAB Update, 3(3), 1-2

WORLD HEALTH ORGANIZATION (1992) The ICD-10 Classification of Mental and Behavioural Disorders. Geneva:WHO.

Richard Lucas Consultant Psychiatrist, St Ann's Hospital, London N15 3TH. Consultant Psychiatric Member of the Disability Living Allowance Advisory Board

\title{
A survey of psychiatrists' and nurses' views of mental health advocacy
}

\section{AIMS AND METHOD}

Advocacy is assuming an increasingly important role in the delivery of mental health services, but many psychiatrists feel threatened by it. This study was performed to ascertain how much doctors and nurses know about advocacy and their attitudes towards it. We interviewed five senior house officers, five staff nurses and four community psychiatric nurses (CPNs) to examine their understanding, experience and opinions about advocacy. A full- time advocate was also interviewed to establish his views about how well staff understood his role.

\section{RESULTS}

In general there was poor understanding of the background and training of advocates, and their Code of Practice. There were also important differences in the way in which different groups of staff saw advocacy, with CPNs having the best understanding. Experiences of advocacy were positive and it was seen as being helpful both for clients and staff, despite fears that advocates might work to their 'own agendas'.

\section{CLINICAL IMPLICATIONS}

There is a need to improve psychiatrists' understanding of what advocacy is, through the involvement of advocates and service users in their training. This would help to allay their anxieties about the role of advocates.
To advocate is to speak on behalf of someone else. Peer advocacy, as defined by the UK Advocacy Network

(UKAN), is "support from advocates who themselves use or have used mental health services" (Conlan et al, 1994). This is an important provision, especially for those detained under a section of the Mental Health Act because of the powers given to staff. Under these circumstances advocacy is valuable, and has an important ethical function (Thomas \& Bracken, 1999). Peer advocates are independent of mental health service staff and have usually had first-hand experience of using mental health services themselves. They can therefore be seen as 
working for the patient rather than the staff. UKAN has written a Code of Practice for advocates, defining peer advocacy:

special articles
"Advocates will only act or speak on the user's behalf as the user wishes. The key aim is to help people regain their own power and speak for themselves.... Advocates are there to speak with, rather than for, people whenever possible.... The advocate should make no decisions or choices on behalf of the service user. ... Advocates should not give advice or counselling. . . Advocates must not act as mediators. .." (Conlan et al, 1994) At present psychiatric patients only have access to advocacy if they specifically request it, a method of recruitment that tends to reinforce the paternalism of mental health services, which advocacy is there to challenge. For this reason it has been argued that new mental health legislation should include a statutory right to advocacy as part of the principle of reciprocity, given that compulsory treatment in the community represents a significant erosion of civil liberties. The Green Paper proposing reform of the Mental Health Act recommends that a "statutory right to advocacy is created at the earliest opportunity", specifically for those "subject to compulsory powers" (Secretary of State for Health, 1999). If implemented, this would have significant resource implications and result in changes to the way mental health services manage compulsory patients. The difficulty is that there is a belief that advocates are 'antipsychiatry' and undermine the work of mental health professionals (Gamble, 1999). Such negative attitudes are likely to stand in the way of any potential benefits of advocacy, so it is important that we clarify the attitude of psychiatrists and other mental health professionals towards advocacy. For this reason we interviewed junior medical and nursing staff to establish how much they knew about advocacy, their attitudes towards it and the effect it had on their practice.

\section{Methods}

Five senior house officers (SHOs) in psychiatry, five staff nurses working on an acute psychiatry in-patient unit in Bradford and four community psychiatric nurses (CPNs) were invited to participate on the basis of their availability at the time of the study. Nobody declined to be interviewed. These three groups were chosen because they represent the staff groups most likely to encounter mental health advocacy in their daily work. They are also the groups who have most contact with patients, and are thus in a good position to be able to discuss the role that advocacy may play in patient care. The junior doctors had worked in psychiatry for between 12 and 36 months. All the participants were interviewed by means of a semistructured interview to establish their knowledge of advocacy, their experiences of it and their opinions about it. These key issues were represented by a series of questions (Appendix 1) to enable the subjects to explore the issues as fully as possible. These questions were formulated following discussions about the training and work of advocates with the manager of the Bradford and Airedale Mental Health Advocacy Group, and the cochair of UKAN.
UKAN is the principal organisation in this country that has taken a lead in developing and extending the work of peer advocacy (that is, advocacy for patients by people with experience of using mental health services), although some advocacy services are provided by other organisations such as Mind and the National Schizophrenia Fellowship. UKAN has produced a Code of Practice for advocates (Conlan et al, 1994), as well as a training manual. Training is patient-led and deals with the Mental Health Act, patient rights and the principles of advocacy, as well as local issues. There is no qualification for advocates because UKAN considers that this may discourage those who have the potential to be good advocates, but who may have anxieties about formal study. UKAN acknowledges that there is much national variation in the way in which advocates are trained. The Bradford and Airedale Mental Health Advocacy Group, who are responsible for training the advocates that staff in this study would have encountered, offers a 30-hour course over 15 weeks, which involves external speakers (P.T. has spoken about the role of the consultant psychiatrist in mental health services), videotapes, role play, visits to the local psychiatric hospital and case discussions. The group uses the UKAN Code of Practice and training manual.

The SHOs were interviewed by Y.L. in the junior doctors' mess, and staff nurses in interview rooms on the in-patient unit. The CPNs were interviewed in the resource centres where they worked. No names were recorded, to allow anonymity, so the subjects felt more at liberty to speak openly. The interviews with the SHOs were conducted when there were as few people around as possible, and those with nurses in total privacy. Each interview lasted up to 10 minutes. Ideally interviews should have been tape recorded, but shortage of resources meant that it was not possible to transcribe and analyse the interviews, so written notes of subjects comments were made instead. The notes were subsequently examined by Y.L. using a simple form of content analysis in which the keywords and points made for questions 1-4 and 7-9, and all details recorded for questions 5 and 6, were extracted (see Appendix 1). These were summarised by profession to compare each group's responses. This made it possible to compare the subjects' knowledge with the way in which advocates were trained and worked locally. A part-time advocate working on the in-patient unit for Bradford and Airedale Mental Health Advocacy Group was interviewed to find out how he felt staff understood his role, his experiences of working with staff and his opinions on the impact of advocacy for staff and clients. He was interviewed in an interview room on a ward in Lynfield Mount Hospital.

\section{Results}

\section{What do staff know about advocacy in mental health?}

All five SHOs used expressions such as 'voice a client's opinion', 'on behalf' or 'representing' to describe the role 
of the advocate. Two used the terms 'independent' and 'non-judgemental', which suggests that they regarded advocates as having an objective position. None of the staff nurses raised objectivity, but four of them described advocates as representing the client. They also mentioned the provision of advice regarding welfare rights. One CPN discussed objectivity and three discussed representing the client. Three subjects said that advocates enabled clients to speak for themselves.

None of the subjects knew anything about advocates' backgrounds, their training or Code of Practice, although all subjects knew a specific advocate. Four thought they worked in the voluntary sector. Seven said that advocates were previous patients but three thought they were lawyers. No one actually knew how advocates were trained, or who was responsible for training. One CPN did accurately describe training, but he explained that this was how he imagined it would be because this was how he would do it. This supports the advocate's statement that the CPNs best understood his role. None of the subjects knew anything about the Code of Practice. Some did not know there was one.

\section{What experiences had they had of working with advocates?}

All the CPNs had experience of working with advocates, and all but one SHO and one staff nurse had had such experience. SHOs and staff nurses usually encountered advocates on ward rounds, and on occasions SHOs had been approached directly by the part-time advocate on the ward. Some CPNs actually suggested to their clients that advocacy might be helpful for them. Three of the SHOs described positive experiences about an advocate expressing patients' views. Two SHOs recalled negative experiences in which they claimed that advocates had forced their own views on to patients and had made demands on staff. Staff nurses had encountered advocates on ward rounds. Two staff nurses described occasions where they had involved an advocate with a patient. The CPNs all described positive experiences with advocates, in which the advocate represented the client's views, particularly in situations where the client found it difficult to put his or her own views forward.

\section{What are their opinions regarding the value of advocacy for staff?}

Most subjects had found advocacy useful. One SHO thought that it was unhelpful and another thought "it kept patients happy". Two said that it was good that staff knew what patients wanted, but two said that advocacy had no impact on the management of patients. All except one of the staff nurses thought that advocacy was useful for staff, but they also believed that mediation was an important part of advocacy. One described a negative experience in which an advocate had put across the client's view without mediating. Two other staff nurses also mentioned the role of mediation (as opposed to representation), and two referred to advocacy challen- ging their own thinking about patient management. Two expressed concern about what they described as advocates' "other motivations", giving too much advice based on their own opinion. All the CPNs had found their experience of advocacy helpful. Two believed that advocacy challenged how the patient is managed. One said that it "reminds staff where patients come from". One CPN said that advocacy helped staff who wanted a patient to be heard, even though they disagreed with the patient. He felt that they would be failing in their professional responsibility if they represented the patient's view themselves. One CPN believed that advocacy did not change patient management and one said it was unhelpful when advocates worked "to their own agenda(s)", although he had not experienced an advocate who had.

\section{What are their opinions regarding the value of advocacy for patients?}

All staff recognised the value of advocacy for patients. Four SHOs believed that advocacy was valuable for patients, although one was uncertain. Two felt that for advocacy to be helpful, the advocate must represent the client's wishes and not put forward his or her own opinions. All the staff nurses believed that advocacy was helpful for clients. Two believed that an advocate empowers the client, giving him/her greater control over his/her management. Likewise, all the CPNs believed that advocacy was valuable. One commented that without an advocate a client might not "put points forward".

\section{Discussion}

The study was limited in that we were only able to interview 14 subjects on the basis of their availability at the time. We have no way of knowing how representative the views and experiences presented here are of their colleagues, either locally or nationally. The results do suggest that larger national comparisons are indicated, especially given the high level of interest in advocacy at the moment. Only two of the staff interviewed had no experience of working with advocates and seven said they had much experience. Bradford and Airedale Advocacy Group has a part-time advocate working at Lynfield Mount Hospital and others work in the community. In defining the role of the advocate, most subjects regarded objectivity and representation as key points. Relatively little was said about enabling clients to speak for themselves - the key objective as far as the advocate was concerned. There was also a poor level of understanding of the background, training and Code of Practice of advocates. Despite this, experiences with advocates were generally positive and advocacy was seen as helpful to both staff and clients. This was confirmed by the advocate, who felt that most staff were positive about his role. Despite this, there were fears that advocates might work to their own agendas and thus cause problems for staff. The advocate acknowledged this as a potential problem if advocates do not adhere to the Code of 
(8)

special articles
Practice but in his view this is rare and advocacy services usually detect such individuals and deal with them.

Some subjects, especially staff nurses, expressed the idea that advocacy involves mediation between staff and patients. Mediation implies acting as a go-between for two parties in dispute, in which case an advocate would be expected to represent both the professional's and patient's positions. The UKAN Code of Practice states quite clearly that this is not the role of an advocate, and stresses the representation of the patient's position. This accords with the advocate's experience that some staff nurses did not understand this role. There was also a suggestion that advocates bring their own opinions into clinical situations, despite the fact that advocates are specifically trained to represent the patient's view and not their own. Campbell and Lindow (1997), in a publication for the Royal College of Nursing, point out that nurses should "understand the difference between acting in the person's best interest and acting to enable the person to say what they want". This distinction is important. By representing the client rather than trying to work in their best interests, or mediating between staff and clients, advocates are combating the "dangers of unchecked medical paternalism in psychiatry" (Thomas \& Bracken, 1999).

Although SHOs made some negative comments, there was no evidence of widespread fears that advocates would "promote their own anti-medical establishment political agenda" (Gamble, 1999). We have worked hard in Bradford to establish good relationships with local user groups, such as Mind and the Bradford and Airedale Mental Health Advocacy Group. These efforts have been rewarded by the active involvement of patients in the locally organised training scheme for SHOs (P.T. is one of the college tutors). In the academic term preceding this study (Autumn 1999) patients gave presentations on advocacy, self-injury and electroconvulsive therapy to the postgraduate psychiatrists in Bradford. The junior doctors interviewed here had probably had more exposure to patient perspectives than their colleagues elsewhere, yet despite this there is clearly room for improvement in their understanding of advocacy. In general, there would appear to be no grounds to be sanguine about psychiatrists' attitudes towards advocacy, and in view of the increasing prominence that advocacy will play in the future it is essential that the Royal College of Psychiatrists takes steps to ensure that all junior doctors are exposed to advocates in their training.

\section{Acknowledgements}

We are grateful to Judith Gay and Andrew Perry from Bradford and Airedale Mental Health Advocacy Group and to Ethna Kilduff from UK Advocacy Network for their help and advice in undertaking this study, and writing it up. We are also grateful to the junior doctors and nursing staff who agreed to participate in the study.

\section{References}

CAMPBELL, P. \& LINDOW, V. (1997) Changing Practice. Mental Health Nursing and User Empowerment. Royal College of Nursing Learning Materials on Mental Health. London: RCN

CONLAN, E., et al (1994) Advocacy A Code of Practice. Developed by UKAN. London: Mental HealthTask Force User Group.

GAMBLE, D. (1999) The value of advocacy: putting ethics into practice. Psychiatric Bulletin, 23, 569-570.

Yvonne Lacey Medical Student, University of Leeds,

*PhilipThomas Senior Research Fellow and Consultant Psychiatrist, Bradford Assertive OutreachTeam, 48 Ashgrove, Bradford BD7 1BL

\section{Appendix}

What do you know about advocacy?

1 What is the role of an advocate?

2 Who are advocates?

3 How are advocates trained?

4 What do you know about their code of practice?

Experience with advocacy

5 Have you had any experience of working with advocates?

6 If yes, could you describe an example of a situation where an advocate was involved?

Opinions about advocacy

7 Is advocacy helpful to staff?

8 Is advocacy helpful to clients?

9 Is it unhelpful at all? 